\title{
Unity Power Factor Control Of Hybrid Excited Axial Field Flux-Switching Permanent Magnet Machine
}

\author{
Jilong Zhao ${ }^{1 *}$, Member, IEEE, Mengdie Jing ${ }^{1}$, Xiangdong Sun ${ }^{1}$, and Nian $\mathrm{Li}^{2}$ \\ ${ }^{1}$ School of Automation and Information Engineering, Xi' an University of Technology, China \\ ${ }^{2}$ School of Electrical, Mechanical and Mechatronic Systems, University of Technology Sydney, Australia \\ Email: jlzhao@xaut.edu.cn
}

\begin{abstract}
Hybrid excited axial field flux-switching permanent magnet (AFFSPM) (HEAFFSPM) machine is a novel stator-excitation hybrid excited synchronous machine, which combines the advantages of AFFSPM machine and wound-field excitation machine. In this paper, the structure feature of HEAFFSPM machine is analyzed, and the mathematical model is established. In order to improve the power factor of drive system for the HEAFFSPM machine and make full use of the inverter capability, a kind of unity power factor (UPF) control method is proposed, and the operating performance of HEAFFSPM machine is investigated. The validity of the proposed control method is verified by the simulation and experimental research. The results indicate the UPF can be achieved at different speed and load while the constant torque region is extended by using the UPF control method compared with the zero $d$-axis current control.
\end{abstract}

\section{INTRODUCTION}

Recently, the hybrid excited flux-switching permanent magnet (FSPM) (HEFSPM) machines with locating the PMs and windings on stator, which combines the merits of both FSPM machine and wound-field excitation machine, are attracting increasing interest [1]-[5]. Due to high power/torque density, low-speed large-torque capability, as well as compact and robust structure, HEFSPM machines are excellent candidates for variablespeed applications such as wind power generation, ship propulsion, aerospace, rail transportation, hybrid vehicles, etc. The HEFSPM machine has two excitation sources, that is, the PMs and field excitation, which can operate in the flux-enhancing or flux-weakening conditions by controlling the field excitation.

A practical optimal current control method for the nonsalient HESM was presented in [6], but it is not suitable for a doubly-salient HESM because of lager saliency ration. A new flux-weakening strategy of hybrid excited synchronous machine (HESM) for electric/hybrid vehicles traction system was proposed in [7], which extends the speed range of machine. An optimal current control strategy for HESM, guarantying minimal copper and iron losses under satisfying speed and torque requirements, was investigated in [8]. A new control method based on the voltage error for the HEFSPM machine was analyzed in [9], which is independent of machine parameters, and provides a smooth speed transition between flux-enhancing and flux-weakening operation region. The validity of aforementioned methods is verified by simulation or experiment, however, the problem of lower power factor exists in drive system.

The hybrid excited axial field flux-switching permanent magnet (HEAFFSPM) machine is a novel HEFSPM machine [10], as shown in Fig.1, which exhibits the advantages of high power/torque density, low-speed large-torque, and wide speed-range owing to the fluxfocusing effect, shorter axial length, double stator, and the hybrid excitation. In this paper, in order to improve the power factor of drive system, a new unity power factor (UPF) control strategy for the HEAFFSPM machine is proposed.

This paper is organized as follows. In Section II, the topology of HEAFFSPM machine is analyzed. The mathematical model of HEAFFSPM machine is deduced in Section III. Afterward, a detailed analysis of the proposed UPF and $i_{\mathrm{d}}=0$ control strategy for HEAFFSPM machine is presented and the control system is established. Then, in Section IV, the simulation and experimental research are carried to verify the validity of the proposed control strategy. Section V concludes this paper.

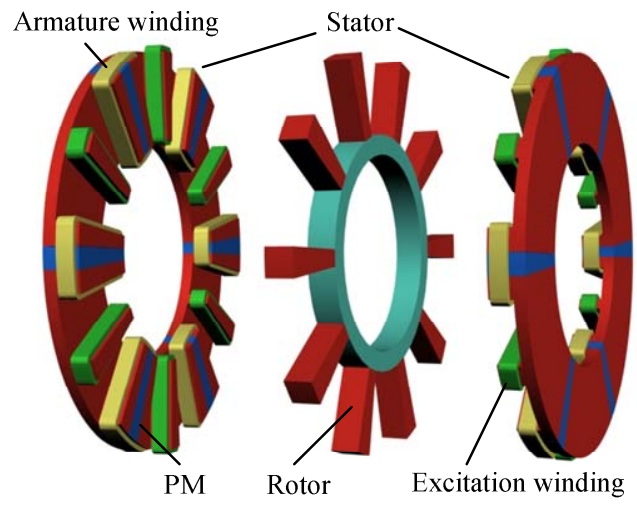

Fig.1. Topology of HEAFFSPM machine

\section{TOPOLOGY OF HEAFFSPM MACHINE}

A three-phase 12-stator-slot/10-rotor-pole HEAFFSPM machine, which is composed of two same outer stators and one inner rotor with doubly salient structure, is illustrated in Fig.1. The PMs with interlaced magnetizing, concentrated armature and field windings are altogether located in the stator. There are neither PMs nor windings in the rotor, which improves the robustness of rotor and makes the heat dissipation easier. The stator contains six 'E'-shaped laminated segments, PMs, armature and field 
windings. The PMs are sandwiched in the 'E'-shaped laminated segments and the field windings are coiled in the middle teeth of 'E'-shaped laminated segments, which provide physical and magnetic isolation between phase and phase. The opposite polarity PMs in the two stators are circumferentially aligned with each other. The parallel PM and excitation field form together the air gap field along axial direction, which avoids the risk of an irreversible demagnetization, and can regulate flexibly the air gap field.

\section{CONTROL STRATEGY}

\section{A. Mathematical Model}

Neglecting the influence of the temperature, magnetic saturation, and the hysteresis loss, the HEAFFSPM machine can be described in a $d-q$ reference frame, as shown in Fig. 2 .

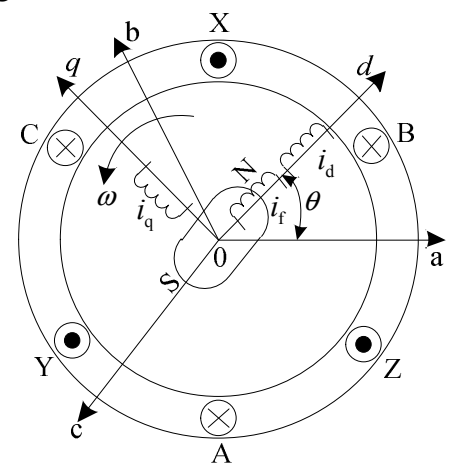

Fig.2. Model of HEAFFSPM machine in $d-q$ reference frame

Based on the proposed model, the flux-linkage equations of HEAFFSPM machine can be obtained as

$$
\left[\begin{array}{l}
\psi_{\mathrm{d}} \\
\psi_{\mathrm{q}} \\
\psi_{\mathrm{f}}
\end{array}\right]=\left[\begin{array}{ccc}
L_{\mathrm{d}} & 0 & M_{\mathrm{f}} \\
0 & L_{\mathrm{q}} & 0 \\
3 M_{\mathrm{f}} / 2 & 0 & L_{\mathrm{f}}
\end{array}\right]\left[\begin{array}{c}
i_{\mathrm{d}} \\
i_{\mathrm{q}} \\
i_{\mathrm{f}}
\end{array}\right]+\left[\begin{array}{c}
\psi_{\mathrm{m}} \\
0 \\
0
\end{array}\right]
$$

where $\psi_{\mathrm{d}}, \psi_{\mathrm{q}}, \psi_{\mathrm{f}}$, and $\psi_{\mathrm{m}}$ are the $d$-axis, $q$-axis, excitation, and the PM flux linkages, respectively; $i_{\mathrm{d}}, i_{\mathrm{q}}$ and $i_{\mathrm{f}}$ are the $d$-axis, $q$-axis and excitation currents, respectively; $L_{\mathrm{d}}, L_{\mathrm{q}}$ are the $d$ - and $q$-axis inductance, respectively; $L_{f} i$ is the excitation windings self-inductance; $M_{f}$ is the mutual inductance between the armature and excitation windings;

The voltage equations can be described as

$$
\left\{\begin{array}{l}
u_{\mathrm{d}}=R_{\mathrm{s}} i_{\mathrm{d}}+\frac{\mathrm{d} \psi_{\mathrm{d}}}{\mathrm{d} t}-\omega_{\mathrm{e}} \psi_{\mathrm{q}} \\
u_{\mathrm{q}}=R_{\mathrm{s}} i_{\mathrm{q}}+\frac{\mathrm{d} \psi_{\mathrm{q}}}{\mathrm{d} t}+\omega_{\mathrm{e}} \psi_{\mathrm{d}} \\
u_{\mathrm{f}}=R_{\mathrm{f}} i_{\mathrm{f}}+\frac{\mathrm{d} \psi_{\mathrm{f}}}{\mathrm{d} t}
\end{array}\right.
$$

where $u_{\mathrm{d}}, u_{\mathrm{q}}$ and $u_{\mathrm{f}}$ are the $d$-axis, $q$-axis and excitation voltages, respectively; $R_{\mathrm{s}}, R_{\mathrm{f}}$ are the armature and excitation windings resistance, respectively; $\omega_{\mathrm{e}}$ is the electrical angular frequency.

The electromagnetic torque equation can be written as

$$
T_{\mathrm{e}}=\frac{3}{2} p i_{\mathrm{q}}\left[\psi_{\mathrm{m}}+\left(L_{\mathrm{d}}-L_{\mathrm{q}}\right) i_{\mathrm{d}}+M_{\mathrm{f}} i_{\mathrm{f}}\right]
$$

where $T_{\mathrm{e}}$ is the electromagnetic torque; $p$ is the number of pole pairs.

\section{B. Proposed control strategy}

Ignoring the stator resistance voltage drop, the phase diagram of HEAFFSPM machine is illustrated in Fig.3. $\varphi$ is the power factor angle; $\phi$ is the internal power factor angle; $\delta$ is the power angle.

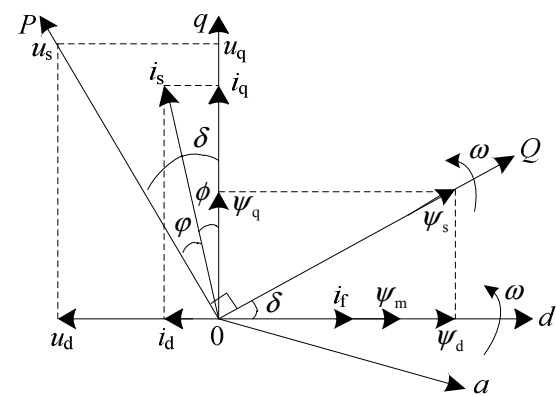

Fig.3. Phase diagram of HEAFFSPM machine

Based on this, the stator $d$ - and $q$-axis current can be expressed as

$$
\left\{\begin{array}{l}
i_{\mathrm{d}}=i_{\mathrm{s}} \sin \phi \\
i_{\mathrm{q}}=i_{\mathrm{s}} \cos \phi
\end{array}\right.
$$

where $i_{\mathrm{s}}$ is the stator armature current.

When the zero $d$-axis current $\left(i_{\mathrm{d}}=0\right)$ control is used for the HEAFFSPM machine, the eq. (3) can be rewritten as

$$
T_{\mathrm{e}}=\frac{3}{2} p i_{\mathrm{q}}\left[\psi_{\mathrm{m}}+M_{\mathrm{f}} i_{\mathrm{f}}\right]
$$

Under low load running, the excitation current $i_{\mathrm{f}}=0$, and the reference current can be obtained as

$$
\left\{\begin{array}{l}
i_{\text {dref }}=0 \\
i_{\text {qref }}=\frac{2 T_{\text {eref }}}{3 p \psi_{\mathrm{m}}} \\
i_{\text {fref }}=0
\end{array} \quad\left(T_{\mathrm{L}} \leq \frac{3}{2} p \psi_{\mathrm{m}} i_{\mathrm{qN}}\right)\right.
$$

At overload or starting, the reference current can be got as

$$
\left\{\begin{array}{l}
i_{\text {dref }}=0 \\
i_{\text {fref }}=\frac{2 T_{\text {eref }}-3 p \psi_{\mathrm{m}} i_{\mathrm{qN}}}{3 p M_{\mathrm{f}} i_{\mathrm{qN}}} \\
i_{\text {qref }}=i_{\mathrm{qN}}
\end{array} \quad\left(T_{\mathrm{L}}>\frac{3}{2} p \psi_{\mathrm{m}} i_{\mathrm{qN}}\right)\right.
$$

where $i_{\text {dref, }} i_{\text {qref, }}$ and $i_{\text {fref }}$ are the $d$-, $q$-axis and excitation reference current, respectively; $T_{\text {eref }}$ is the electromagnetic torque reference value; $T_{\mathrm{L}}$ is the load torque; $i_{\mathrm{qN}}$ is the $q$ axis rated current.

As shown in Fig.3, when the $i_{\mathrm{d}}=0$ control is employed, $\phi=0, \varphi=\delta, i_{\mathrm{q}}=i_{\mathrm{s}}$, the flux-linkage eq. (1) can be reexpressed as

$$
\left\{\begin{array}{l}
\psi_{\mathrm{d}}=\psi_{\mathrm{exc}}=\psi_{\mathrm{m}}+M_{\mathrm{f}} i_{\mathrm{f}} \\
\psi_{\mathrm{q}}=L_{\mathrm{q}} i_{\mathrm{q}}=L_{\mathrm{q}} i_{\mathrm{s}}
\end{array}\right.
$$

where $\psi_{\mathrm{exc}}$ is the total excitation flux linkage.

Thus, the power factor of HEAFFSPM machine can be described as

$$
\cos \varphi=\cos \delta=\frac{\psi_{\mathrm{d}}}{\sqrt{\psi_{\mathrm{d}}^{2}+\psi_{\mathrm{q}}^{2}}}=\frac{1}{\sqrt{1+\left(\frac{L_{\mathrm{q}} i_{\mathrm{s}}}{\psi_{\mathrm{m}}+M_{\mathrm{f}} i_{\mathrm{f}}}\right)^{2}}}
$$

When the machine is running at the light load or rated 
load, considering the eq. (6) and (9), the power factor can be rewritten as

$$
\cos \varphi=\frac{1}{\sqrt{1+\left({ }_{\mathrm{q}}^{L_{\mathrm{s}}} / \psi_{\mathrm{m}}\right)^{2}}}
$$

As seen in eq. (10), the power factor will become lower gradually with the increasing load.

When the machine is running at the starting or heavy load, based on the eq. (7) and (9), the power factor can be expressed as

$$
\cos \varphi=\frac{1}{\sqrt{1+\left[L_{\mathrm{q}}^{L_{\mathrm{qN}}} /\left(\psi_{\mathrm{m}}+M_{\mathrm{f}} i_{\mathrm{f}}\right)\right]^{2}}}
$$

From (11), when the $q$-axis current increases to the rating current, the power factor reaches to minimum. Then, the power factor can improve with the increasing excitation current. However, when the excitation current achieves the rating value, the power factor is still lower.

Based on the above analysis, when the $i_{\mathrm{d}}=0$ control is used for the machine, there exists the problem of lower power factor in the drive system. To improve the power factor of the drive system, a kind of UPF control strategy is proposed in this paper.

The UPF control strategy is implemented by holding the voltage and current vectors have same phase. According to the Fig. $3, \varphi=0^{\circ}, \phi=\delta$, the following formula can be obtained as

$$
\frac{i_{\mathrm{d}}}{i_{\mathrm{q}}}=\frac{u_{\mathrm{d}}}{u_{\mathrm{q}}}=\frac{-\omega_{\mathrm{e}} L_{\mathrm{q}} i_{\mathrm{q}}}{\omega_{\mathrm{e}}\left(\psi_{\mathrm{m}}+L_{\mathrm{d}} i_{\mathrm{d}}+M_{\mathrm{f}} i_{\mathrm{f}}\right)}
$$

When the load torque is less than or equal to the rated torque, the excitation current is zero, combining the eq. (3) and (12), the $d$-axis, $q$-axis and excitation reference current can be described as

$$
\left\{\begin{array}{l}
i_{\text {qref }}=\sqrt{i_{\text {dref }}\left(\psi_{\mathrm{m}}+L_{\mathrm{d}} i_{\text {dref }}\right) / L_{\mathrm{q}}} \\
i_{\text {fref }}=0 \\
2 T_{\mathrm{e}} / 3 p=\sqrt{i_{\text {dref }}\left(\psi_{\mathrm{m}}+L_{\mathrm{d}} i_{\text {dree }}\right) / L_{\mathrm{q}}}\left[\psi_{\mathrm{m}}+i_{\text {dref }}\left(L_{\mathrm{d}}-L_{\mathrm{q}}\right)\right]
\end{array}\right.
$$

When the load torque is greater than the rated torque, the excitation current is maintained to the rated value and the machine operates in the flux-enhancing conditions. The unity power factor is achieved through coordination control $i_{\mathrm{d}}$ and $i_{\mathrm{q}}$. According to the eq. (3) and (12), the $d$ axis, $q$-axis and excitation reference current can be expressed as

$$
\left\{\begin{array}{l}
i_{\mathrm{qref}}=\sqrt{\frac{i_{\text {dref }}\left(\psi_{\mathrm{m}}+L_{\mathrm{d}} i_{\text {dref }}+M_{\mathrm{f}} i_{\mathrm{NN}}\right)}{L_{\mathrm{q}}}} \\
i_{\text {fref }}=i_{\mathrm{N}} \\
\frac{2 T_{\mathrm{e}}}{3 p}=\left[\psi_{\mathrm{m}}+i_{\text {dref }}\left(L_{\mathrm{d}}-L_{\mathrm{q}}\right)+M_{\mathrm{f}} i_{\mathrm{N}}\right] \sqrt{\frac{i_{\text {dref }}\left(\psi_{\mathrm{m}}+L_{\mathrm{d}} i_{\text {dref }}+M_{\mathrm{f}} i_{\mathbb{N}}\right)}{L_{\mathrm{q}}}}
\end{array}\right.
$$

Based on this control strategy, the schematic diagram of vector control system for the HEAFFSPM machine is established, as shown in Fig.4.

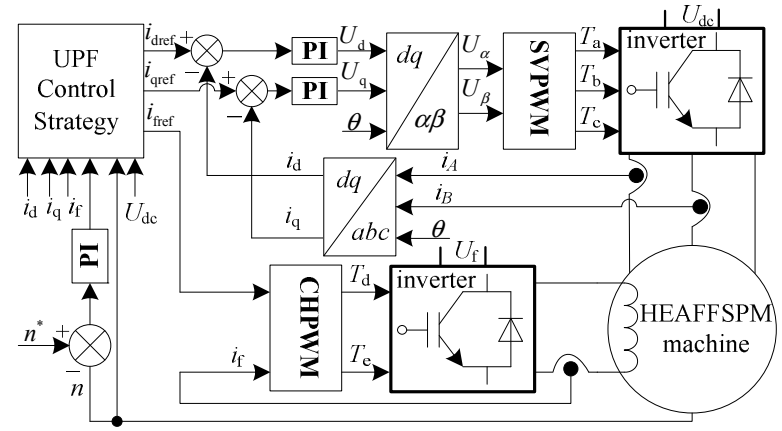

Fig.4. Schematic diagram of drive system for HEAFFSPM machine

\section{SimUlATION AND EXPERIMENT}

In order to investigate the operating performance of the HEAFFSPM and demonstrate the validity of the proposed strategy, the simulations and experiments are constructed based on MATLAB and dSPACE1103, respectively. The experiment platform is shown in Fig.5.

TABLE I

PARMETERS OF HEAFFSPM MACHINE

\begin{tabular}{cccc}
\hline parameters & value & parameters & value \\
\hline$U_{\mathrm{dc}}(\mathrm{V})$ & 200 & $\psi_{\mathrm{m}}(\mathrm{Wb})$ & 0.1 \\
$n_{\mathrm{N}}(\mathrm{r} / \mathrm{min})$ & 750 & $R_{\mathrm{s}}(\Omega)$ & 3.4 \\
$T_{\mathrm{N}}(\mathrm{N} \cdot \mathrm{m})$ & 6.5 & $R_{\mathrm{f}}(\Omega)$ & 7.8 \\
$I_{\mathrm{N}}(\mathrm{A})$ & 3.8 & $L_{\mathrm{d}}(\mathrm{mH})$ & 10.43 \\
$U_{\mathrm{f}}(\mathrm{V})$ & 300 & $L_{\mathrm{q}}(\mathrm{mH})$ & 13.87 \\
$I_{\mathrm{fN}}(\mathrm{A})$ & 3 & $L_{\mathrm{f}}(\mathrm{mH})$ & 20 \\
$p$ & 10 & $M_{\mathrm{f}}(\mathrm{mH})$ & 8.4 \\
\hline
\end{tabular}

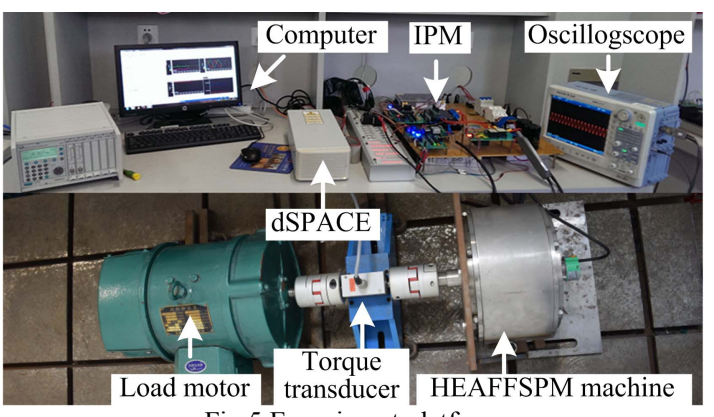

Fig.5 Experiment platform

\section{A. Simulation Analysis}

A speed command of $n=600 \mathrm{r} / \mathrm{min}$ with load torque of $5 \mathrm{~N} \cdot \mathrm{m}$ is given. Before $t=1 \mathrm{~s}$, the machine operates in the $i_{\mathrm{d}}=0$ control mode. When $t=1 \mathrm{~s}$, the UPF control is activated. The $i_{\mathrm{d}}=0$ control is chose again at $t=2 \mathrm{~s}$. The load is increased to $11 \mathrm{~N} \cdot \mathrm{m}$ at $t=3 \mathrm{~s}$. When $t=4 \mathrm{~s}$, the UPF control is adopted again. The simulation results are shown in Fig. 6.

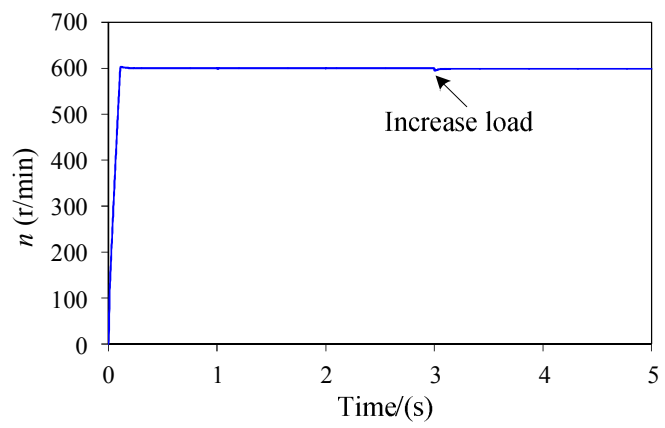

(a) Speed 


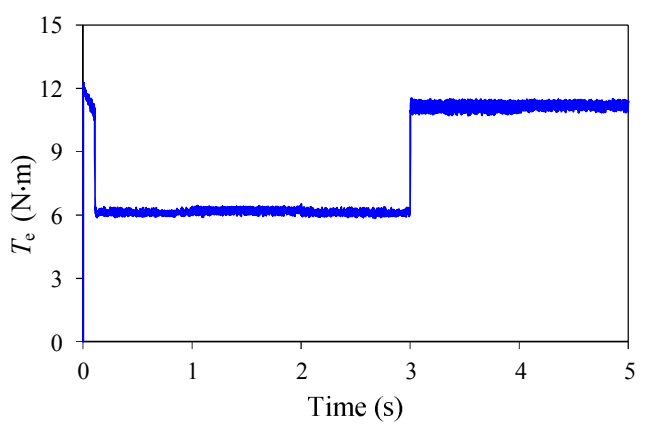

(b) Electromagnetic torque

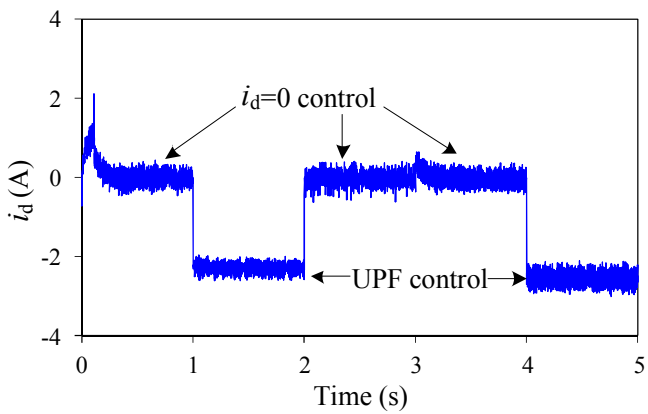

(c) $d$-axis current

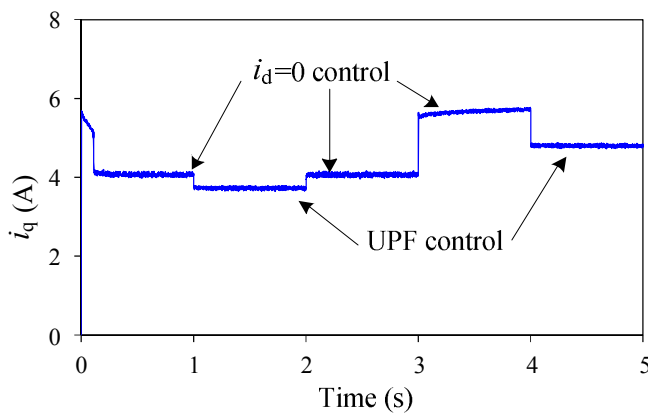

(d) $q$-axis current

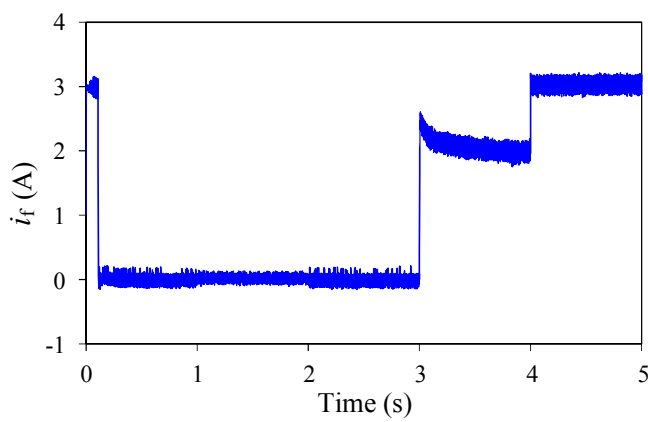

(e) Excitation current

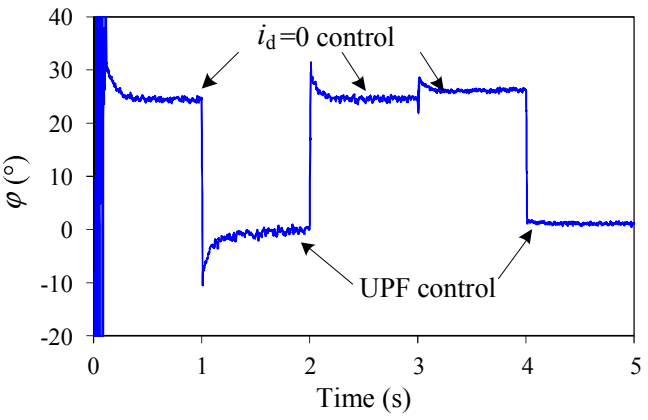

(f) Power factor angle

Fig. 6 Simulation results

The $q$-axis current $i_{\mathrm{q}}$ and excitation current $i_{\mathrm{f}}$ quickly reach the rated values of $5.7 \mathrm{~A}$ and $3 \mathrm{~A}$ to reduce the starting time when startup. After steady-state operation, the $d$-axis current $i_{\mathrm{d}}$ is about $0 \mathrm{~A}$ because of the $i_{\mathrm{d}}=0$ control, and the power factor angle is about $24.5^{\circ}$. The UPF control is employed at $t=1 \mathrm{~s}$, the $i_{\mathrm{d}}, i_{\mathrm{q}}$ and $i_{\mathrm{f}}$ are -2.3 $\mathrm{A}, 3.8 \mathrm{~A}$ and $0 \mathrm{~A}$ respectively, and the power factor angle is $0^{\circ}$. The $i_{\mathrm{d}}=0$ control is chose again at $t=2 \mathrm{~s}$, and the power factor angle returns to $24.5^{\circ}$. At $t=3 \mathrm{~s}$, the load is increased to $11 \mathrm{~N} \cdot \mathrm{m}$, and the $i_{\mathrm{q}}$ reaches the rated value. The flux-enhancing control is activated, the $i_{\mathrm{f}}$ is about 2.1 $\mathrm{A}$, and the power factor angle is $26.2^{\circ}$. It's obvious that the power factor angle increases with the increasing load. The UPF control is employed again at $t=4$, and the $i_{\mathrm{f}}$ reaches the rated value of $3 \mathrm{~A}$. The $i_{\mathrm{d}}$ and $i_{\mathrm{q}}$ are about 2.6 A and 4.8 A respectively, and the power factor angle is $0^{\circ}$. The above-mentioned results are consistent with theoretical analysis, and the validity of proposed UPF control strategy for the HEAFFSPM machine is verified.

\section{B. Experimental Research}

A speed command of $500 \mathrm{r} / \mathrm{min}$ with no-load is given. The $i_{\mathrm{d}}=0$ control is employed when startup. The load of 7 $\mathrm{N} \cdot \mathrm{m}$ is increased at $t=7 \mathrm{~s}$, and the UPF control is adopted at $t=10 \mathrm{~s}$. When $t=13 \mathrm{~s}$, the $i_{\mathrm{d}}=0$ control is chose again, and the load of $7 \mathrm{~N} \cdot \mathrm{m}$ is decreased at $t=16 \mathrm{~s}$.

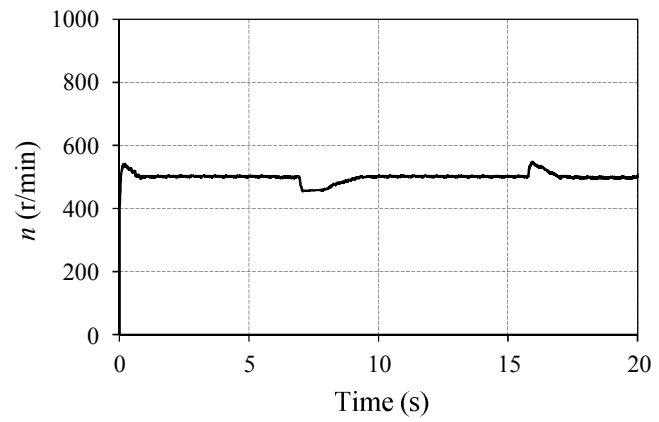

(a) Speed

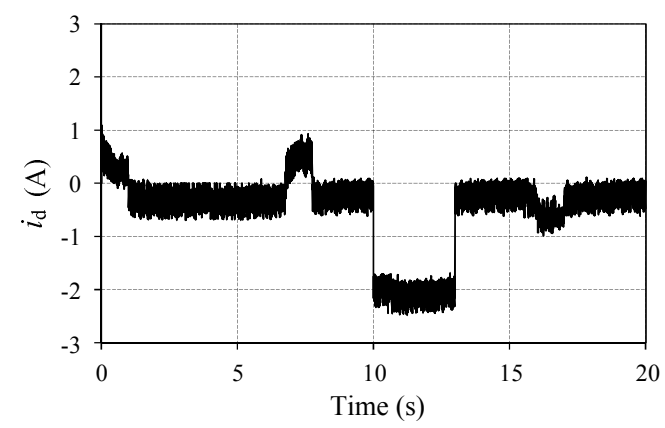

(b) $d$-axis current

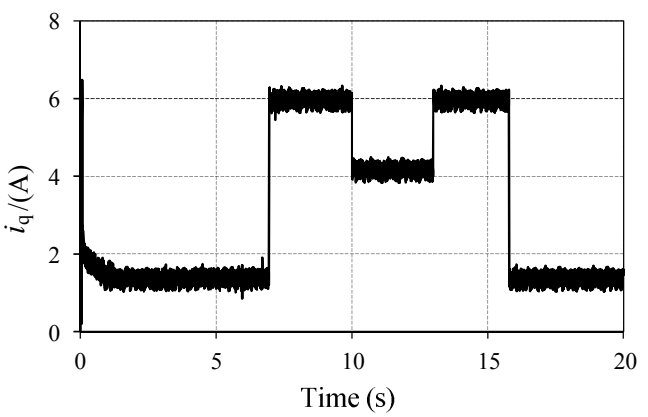

(c) $q$-axis current 


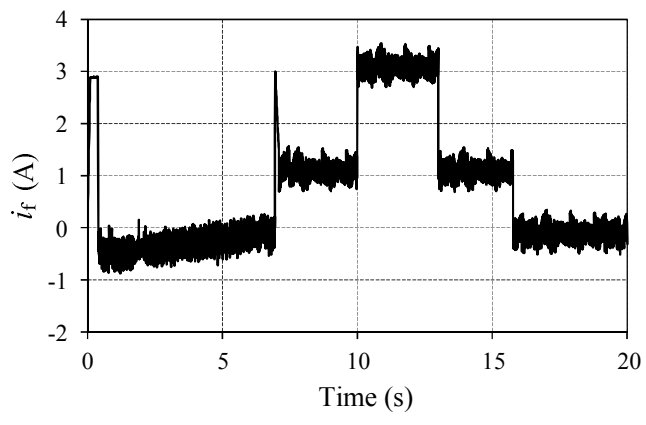

(d) Excitation current

Fig. 7 Experimental results

The experimental results are shown in Fig. 7. When starting, the $i_{\mathrm{q}}$ and $i_{\mathrm{f}}$ increase quickly for reducing the runup time. At steady-state operating, the $i_{\mathrm{d}}$ and $i_{\mathrm{f}}$ are also 0 $\mathrm{A}$, and the $i_{\mathrm{q}}$ is about $1.4 \mathrm{~A}$ due to the cogging torque and friction. At $t=7 \mathrm{~s}$, the load of $7 \mathrm{~N} \cdot \mathrm{m}$ is increased, and the $i_{\mathrm{q}}$ reaches the rated value of $5.7 \mathrm{~A}$. The armature current cannot meet load requirement, and the $i_{\mathrm{f}}$ of $1.2 \mathrm{~A}$ is used to flux-enhancing. The UPF control is employed at $t=10 \mathrm{~s}$, the $i_{\mathrm{d}}, i_{\mathrm{q}}$ and $i_{\mathrm{f}}$ are $-2.2 \mathrm{~A}, 4.2 \mathrm{~A}$ and $3 \mathrm{~A}$, respectively. The $i_{\mathrm{d}}=0$ control is chose again at $t=13 \mathrm{~s}$, and the $i_{\mathrm{d}}, i_{\mathrm{q}}$ and $i_{\mathrm{f}}$ go back to $0 \mathrm{~A}, 5.7 \mathrm{~A}$ and $1.2 \mathrm{~A}$, respectively. When $t=16 \mathrm{~s}$, the load of $7 \mathrm{~N} \cdot \mathrm{m}$ is decreased. As the stepped load increases or decreases, the speed decreases or increases and returns quickly to a given value after adjusting. The validity of the UPF control strategy is verified according to the experimental results.

\section{CONCLUSION}

In this paper, the mathematical model and drive system of HEAFFSPM machine is established, and the operating performance is investigated. The influence of the $i_{\mathrm{d}}=0$ control on the power factor of drive system is analyzed. A kind of UPF control strategy for the HEAFFSPM machine is presented, and compared with the $i_{\mathrm{d}}=0$ control strategy. The simulation and experimental results demonstrate the unity power factor can be achieved at different speed and load, meanwhile, the constant torque region is extended by using the UPF control compared with the $i_{\mathrm{d}}=0$ control. Moreover, the utilization of the inverter capability is improved. The proposed UPF control strategy is also suitable for the other types of HESM.

\section{ACKNOWLEDGMENT}

This work was supported by the National Natural Science Foundation of China $(51277025,51577024)$ and the Nature Science Basic Research Plan in Shaanxi Province of China (2017JQ5077).

\section{REFERENCES}

[1] E. Hoang, H. Ben-Ahmed, and J. Lucidarme, "Switching flux permanent magnet polyphased synchronous machines", Proc. $7^{\text {th }}$ Eur. Power Electronics Application., vol. 3, pp. 903-908, 1997.

[2] Z. Q. Zhu, J. T. Chen, "Advanced Flux-Switching Permanent Magnet Brushless Machines", IEEE Trans. Magn., vol. 46, no. 6, pp. 1447-1453, May 2010.

[3] B. Gaussens, E. Hoang, M. Lécrivain, P. Manfe and M. Gabsi, "A Hybrid-Excited Flux-Switching Machine for High-Speed DC-
Alternator Applications", IEEE Trans. Ind. Electron., vol. 61, no. 6, pp. 2976-2989, June 2014

[4] G. Zhang, W. Hua, M. Cheng and J. Liao, "Design and Comparison of Two Six-Phase Hybrid-Excited Flux-Switching Machines for EV/HEV Applications", IEEE Trans. Ind. Electron., vol. 63, no. 1, pp. 481-493, Jan. 2016.

[5] Arun Gandhi, Leila Parsa, "Double-Rotor Flux-Switching Permanent Magnet machine With Yokeless Stator", IEEE Trans. Energy Convers., vol. 31, no. 4, pp. 1267-1277, Dec. 2016.

[6] Shinnaka, S., Sagawa, T., "New optimal current control methods for energy efficient and wide speed-range operation of hybrid field synchronous motor", IEEE Trans. Ind. Electron, vol. 54, no. 5, pp. 2443-2450, July 2007.

[7] Kefsi, L., Touzani, Y., Gabsi, M, "Hybrid excitation synchronous motor control with a new flux-weakening strategy", IEEE Vehicle Power and Propulsion Conf. (VPPC), Lille (France), Sep. 2010, pp. $1-5$.

[8] R. Mbayed, G. Salloum, L. Vido, E. Monmasson and M. Gabsi, "Hybrid excitation synchronous motor control in electric vehicle with copper and iron losses minimization", 38th Annual Conference on IEEE Industrial Electronics Society(IECON 2012), Montreal (Canada), Dec. 2012, pp. 4886-4891.

[9] N. Pothi, Z. Q. Zhu, I. A. A. Afinowi, B. Lee and Y. Ren, "Control strategy for hybrid-excited switched-flux permanent magnet machines", IET Electric Power App., vol. 9, no. 9, pp. 612-619, Nov. 2015.

[10] Jilong Zhao, Mingyao Lin, Da Xu, Li Lao, and Wei Zhang, "Vector Control of a Hybrid Axial Field Flux-Switching Permanent Magnet Machine Based on Particle Swarm Optimization", IEEE Trans. Magn., vol. 51, no. 11, pp. 8204004 , Nov. 2015. 